\title{
Study on Integrated Evaluation of the Technological Innovation Project in Power Grid Enterprise
}

\author{
Yixin Shi1, a , Zhengyuan Jia2, b and Shijing Li3, c \\ 1/2/3Economics and Management Department, North China Electric Power University, Baoding \\ 071003, China; \\ agooddog813@qq.com
}

Keywords: Integrated Evaluation, Technological Innovation Project Management, ANP, Grey Target Model.

\begin{abstract}
In order to speed up the network “a strong and three-excellent” strategic target,power grid enterprises must increase the technology innovation and management.[2]Integrated evaluation of the technological innovation project in power grid enterprise is an important content of management of technological innovation.Project pre-evaluation taken as the basis of project decision-making and implementation is of great practical significance for improving enterprise's technological innovation projects. The paper establish a system of integrated evaluation of the technological innovation project in power grid enterprise based on the ANP and grey target model.Four power enterprise technical innovation project for instance, verified by constructing the evaluation system has good adaptability.
\end{abstract}

\section{Introduction}

In order to speed up the network “a strong and three-excellent” strategic target,power grid enterprises must increase the technology innovation and management. Integrated evaluation of the technological innovation project in power grid enterprise is an important content of management of technological innovation. According to the time node integrated evaluation is divided into project pre-evaluation and post-evaluation. As the basis of project decision-making and implementation, pre-evaluation has important practical significance for improving grid power enterprise's innovation project decision-making and management level.

Project pre-evaluation is a relatively complete system, including constructing evaluation index system, using the appropriate method figuring out index weighting, using the appropriate model to quantitative analysis the index system, finally making the evaluation conclusions[1].

\section{Building Index System of the Integrated Evaluation of the Technological Innovation Project in Power Grid Enterprise}

\subsection{Building Principle}

Only building up a set of index system that can comprehensively reflect the power grid's technical innovation condition combining the certain model,can work out the evaluation result.This paper follow the following principles in when establish the index system.

(1) Comprehensiveness. The decision of power grid enterprise technical innovation project effected by various factors such as economic,social,technical,environment.In constructing a index system should be comprehensive consideration of the influence factors of innovation project.

(2) Systemic.decision-making of technical innovation project in power grid enterprise is a process affected by many factors. When construct the index system,this paper should consider the relationship between various factors[3].

(3) Practicality.Due to the particularity of power grid enterprise products and importance,the evaluation index should representative and fully reflect the characteristics of power grid enterprises.

\subsection{Building the Index System}

The right project decision is choosing relatively best technical innovation project,being creating economic benefit as the core.basis on technical ability and funding of power grid enterprise,and 
considering grid technology's characteristics and requirements. This paper constructs a set of specific evaluation index.As shown in Table.1:

Table.1 Technical innovation project evaluation index system

\begin{tabular}{cc}
\hline Criteria layer & Indicator layer \\
\hline Enterprise technological innovation ability evaluation & Innovation investment intensity $\left(\mathrm{U}_{11}\right)$ \\
$\mathrm{U}_{1}$ & Innovation organization and management \\
& efficiency $\left(\mathrm{U}_{12}\right)$ \\
& Innovation yields $\left(\mathrm{U}_{13}\right)$ \\
& effectiveness $\left(\mathrm{U}_{21}\right)$ \\
Enterprise technology innovation project evaluation & advancement $\left(\mathrm{U}_{22}\right)$ \\
$\mathrm{U}_{2}$ & Fungibility $\left(\mathrm{U}_{23}\right)$ \\
& reliability $\left(\mathrm{U}_{24}\right)$ \\
& applicability $\left(\mathrm{U}_{25}\right)$ \\
Enterprise technology innovation risk evaluation & production risk $\left(\mathrm{U}_{31}\right)$ \\
$\mathrm{U}_{3}$ & management risk $\left(\mathrm{U}_{32}\right)$ \\
& environmental risk $\left(\mathrm{U}_{33}\right)$ \\
& financial risk $\left(\mathrm{U}_{34}\right)$ \\
\hline
\end{tabular}

\section{Power grid enterprise technical innovation project comprehensive evaluation index weight}

The article chose the G1 method to decide power grid enterprise technical innovation project management evaluation index system's empowerment,as described below.

(1)Ask for experts rearrange the evaluation index according to the importance and form a new order.To form a new index , can be expressed as $X=\left(x_{1}, x_{2}, x_{3}, \ldots \ldots\right)$, and $x_{k-1} \prec x_{k}, k=2,3, \ldots \ldots . . n$.

(2)Given comparison judgment of relative important degree between $x_{k-1}$ and $x_{k}$.After the analysis of the expert's discussion,determine the ratio of relative importance.Represented by:

$$
r_{k}=\frac{w_{k-1}}{w_{k}}(k=2,3, \cdots, n) \cdots \cdots \cdots \ldots \ldots \ldots \ldots \ldots \ldots \ldots(3-1)
$$

Among them, $r_{k}$ 's empowerment reference as shown in table 2:

Table.2 Assignment reference of $r_{k}$

\begin{tabular}{cc}
\hline$r_{k}$ & Implication \\
1.0 & The adjacent two indicators are equally important \\
1.2 & The former slighty important than the latter indicator \\
1.4 & The former obviously important than the latter indicator \\
1.6 & The former strong important than the latter indicator \\
1.8 & The former extremetly important than the latter indicator \\
$1.1,1.3,1.5,1.7$ & Importance between close scores \\
\hline
\end{tabular}

(3)According to the formula3-2:

$$
w_{n}=\left(1+\sum_{k=2}^{n} \prod_{i=k}^{n} r_{i}\right)^{-1}
$$

To calculate the last weight of evaluation index.

(4)According to the formula3-3: 


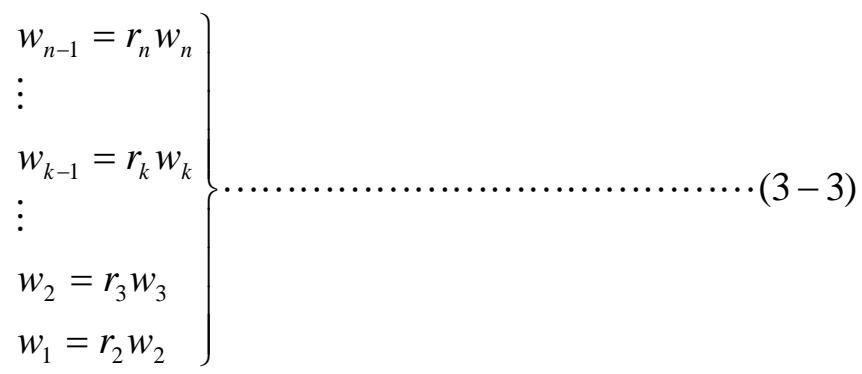

So the other indicators weight are calculated.

have a nice dinner

(5)After getting the weight of all index,switched index back to the original order.

\section{The decision model of Grey Target}

Grey target decision theory is comparing the pros and cons of various programmes,constructing a grey target under the condition of no standad model,with the standard model as the ash of the target,then putting each evaluation scheme index compared with the ash,measuring approaching degree with formula,finally dividing assessment level[4,5,6].

The key problem is calculating the approaching degree.The nearer the distance is the close the off-target distance is and the better the evaluation scheme will be.Otherwise the evaluation scheme is poor.Specific steps are as follows:

(1)To construct the initial matrix

Suppose that there are $\mathrm{n}$ evaluation object or proposed decision scheme,composed of decision solution set $\mathrm{S}$ and organized $\mathrm{n}$ evaluation index or attribute index to form the index set $\mathrm{A}$ :

$$
\begin{aligned}
& S=\left\{S_{1}, S_{2}, \ldots \ldots S_{n}\right\} \\
& A=\left\{A_{1}, A_{2}, \ldots \ldots A_{m}\right\}
\end{aligned}
$$

Effect of sample value of scheme $S_{i}$ to index $A_{j}$

$$
X_{i j}\{i=1, \cdots, \mathrm{n} ; j=1, \cdots, m\}
$$

Effect of sample matrix of solution set $S$ to index set $A$.

$$
X=\left(x_{i j}\right)_{n \times m}
$$

Among them, $x_{i j}$ is the value of $\mathrm{j}$ evaluation index with i investment scheme.

(2)Standardized matrix with non-dimension.

$$
T=\left(t_{i j}\right)_{n \times m}
$$

Because of difference of index physical dimension and magnitude,different indexes cannot be compared directly.So firstly applies dimensionless method to the indexes in order to be compared indexes.

When $x_{i j}$ are the maximum index,

$$
\mathrm{t}_{i j}=\frac{x_{i j}-\min _{i=1,2, \cdots, n} x_{i j}}{\max _{i=1,2, \cdots, n} x_{i j}-\min _{i=1,2, \cdots, n} x_{i j}}
$$

When $x_{i j}$ are the minimum index,

$$
\mathrm{t}_{i j}=\frac{\max _{i=1,2, \cdots, n} x_{i j}-x_{i j}}{\max _{i=1,2, \cdots, n} x_{i j}-\min _{i=1,2, \cdots, n} x_{i j}}
$$

(3)Weighted

Make each calculated index weight multiply standardization and get the weighted standardization matrix:

$$
U=\left(\mathrm{u}_{i j}\right)_{n \times m}=\left(\lambda_{j} t_{i j}\right)_{n \times m}
$$


(4)Determine the bull 's-eye $U_{0}=\left(\mathrm{u}_{01}, \cdots, u_{0 m}\right)$

$$
u_{0 j}=\max \left\{u_{i j}\right\}, i=1,2, \cdots n
$$

(5)Grey target decision,calculating distance to target.

$$
\left|u_{i}-u_{0}\right|=\left[\left(u_{i 1}-u_{01}\right)^{2}+\left(u_{i 2}-u_{02}\right)^{2}+\cdots+\left(u_{i m}-u_{0 m}\right)^{2}\right]^{1 / 2}
$$

If $\left|u_{i}-u_{0}\right|>\left|u_{j}-u_{0}\right|$, then the scheme $\mathrm{j}$ is superior to the scheme $\mathrm{i}$.

\section{Example Analysis}

Now X power supply company plans to implement a technological innovation project.There are three projects to choose,but with limited funds and personnel, $\mathrm{X}$ company can only select one project.Integrated evaluation must be to used to select the best one.Evaluation process as follow:

(1)Project description

Project1:X power supply company plans to add a load to the electronic watch to judge the meter running condition.This technological innovation project improve the level of opposing electricity-stealing work and guarantee the safe operation of power grid enterprise,protecting company's benefit.

Project 2:X company intends to develop relay that effectively prevent coil from rainwater and protect fan motor.

Project 3:X company plans to improve the reliability of contactor sweeper breaker operation.

(2)Assessment process

According the introduce of G1method in third chapter,get weight of each index,then ask 10 power supply enterprise management experts scoring the 3 projects with 10-point scoring method .The wight and score as shown on table3.

\begin{tabular}{|c|c|c|c|c|c|c|c|}
\hline \multirow[t]{2}{*}{ Criteria layer } & \multirow[t]{2}{*}{ Weight } & \multirow[t]{2}{*}{ Indicator layer } & \multirow[t]{2}{*}{ Weight } & \multirow[t]{2}{*}{ Weight } & \multicolumn{3}{|c|}{ Score } \\
\hline & & & & & Project1 & Project2 & Project3 \\
\hline $\begin{array}{c}\text { Enterprise } \\
\text { technological }\end{array}$ & & $\begin{array}{c}\text { Innovation investment } \\
\text { intensity }\left(\mathrm{U}_{11}\right)\end{array}$ & 0.4200 & 0.1260 & 8 & 9 & 6 \\
\hline $\begin{array}{l}\text { innovation ability } \\
\text { evaluation }\left(\mathrm{U}_{1)}\right.\end{array}$ & 0.3000 & $\begin{array}{c}\text { Innovation organization } \\
\text { and management } \\
\text { efficiency }\left(\mathrm{U}_{12}\right)\end{array}$ & 0.3000 & 0.0900 & 8 & 7 & 9 \\
\hline & & Innovation yields $\left(\mathrm{U}_{13}\right)$ & 0.2800 & 0.0840 & 9 & 8 & 9 \\
\hline Enterprise & & effectiveness $\left(\mathrm{U}_{21}\right)$ & 0.3700 & 0.1300 & 9 & 9 & 7 \\
\hline technology & 0.3500 & advancement $\left(\mathrm{U}_{22}\right)$ & 0.2500 & 0.0875 & 7 & 6 & 8 \\
\hline innovation project & & Fungibility $\left(\mathrm{U}_{23}\right)$ & 0.1500 & 0.0525 & 8 & 7 & 5 \\
\hline evaluation $\left(\mathrm{U}_{2}\right)$ & & reliability $\left(\mathrm{U}_{24}\right)$ & 0.1000 & 0.0350 & 7 & 9 & 8 \\
\hline & & applicability $\left(\mathrm{U}_{25}\right)$ & 0.1300 & 0.0445 & 6 & 9 & 5 \\
\hline Enterprise & & production risk $\left(\mathrm{U}_{31}\right)$ & 0.2700 & 0.0945 & 9 & 8 & 6 \\
\hline technology & & management $\operatorname{risk}\left(\mathrm{U}_{32}\right)$ & 0.3200 & 0.1120 & 7 & 8 & 9 \\
\hline innovation risk & 0.3500 & environmental risk $\left(\mathrm{U}_{33}\right)$ & 0.1800 & 0.0630 & 7 & 8 & 5 \\
\hline evaluation $\left(\mathrm{U}_{3}\right)$ & & financial $\operatorname{risk}\left(\mathrm{U}_{34}\right)$ & 0.2300 & 0.0805 & 8 & 7 & 9 \\
\hline
\end{tabular}

Table.3 The index wight and the score of projects

After dimensionless initial evaluation matrix ,get standardized matrix. 


$$
T=\left(\begin{array}{cccccccccccc}
0.6667 & 0.5 & 1 & 1 & 0.5 & 0 & 0 & 0.25 & 0 & 1 & 0.3333 & 0.5 \\
1 & 0 & 0 & 1 & 0 & 0.3333 & 1 & 1 & 0.3333 & 0.5 & 0 & 1 \\
0 & 1 & 1 & 0 & 1 & 1 & 0.5 & 0 & 1 & 0 & 1 & 0
\end{array}\right)
$$

Weighted the standardization:

$U=\left(u_{i j}\right)_{n \times m}=w^{T} T=$

\begin{tabular}{l}
$\left(\begin{array}{llllllll}0.0840 & 0.0450 & 0.0840 & 0.1300 & 0.0438 & 0.0000 & 0.0000 & 0.0111 \\
0.1260 & 0.0000 & 0.0000 & 0.1300 & 0.0000 & 0.0175 & 0.0350 & 0.0445 \\
0.0000 & 0.0900 & 0.0840 & 0.0000 & 0.0875 & 0.0525 & 0.0175 & 0.0000 \\
0.0000 & 0.1120 & 0.0210 & 0.0403 \\
0.0315 & 0.0560 & 0.0000 & 0.0805 \\
0.0945 & 0.0000 & 0.0630 & 0.0000\end{array}\right)$ \\
\hline
\end{tabular}

Determine the bull's-eye:

$U_{0}=\left(\begin{array}{llllllll}0.0840 & 0.0900 & 0.0840 & 0.1300 & 0.0875 & 0.0525 & 0.0350 & 0.0445\end{array}\right.$

$\left.\begin{array}{llll}0.0945 & 0.1120 & 0.0630 & 0.0805\end{array}\right)$

Calculate the bull 's-eye distance:

$$
\left|U_{1}-U_{0}\right|=0.3630 \quad\left|U_{2}-U_{0}\right|=0.1927 \quad\left|U_{3}-U_{0}\right|=0.2124
$$

According to calculating the target distance,the three technical innovation projects can be sort:

$$
U_{2} \succ U_{3} \succ U_{1}
$$

(3)Analysis of the evaluation result

The closer distance the bull's-eye,the better the project is,so that,according to the result, $\mathrm{X}$ company should choose the second project: company intends to develop relay that effectively prevent coil from rainwater and protect fan motor.According to the result project 2 is more effective and reliable,higher applicability.The risk of project 2 rank in the middle.Although project has a worse ability of technical innovation ability,overall,X power supply company invest project 2 is more beneficial for company's future.In order to maximize the interests of the company.

\section{Conclusion}

This paper constructs the index system of integrated evaluation of the technological innovation project in power grid enterprise,then evaluates power grid enterprise technological innovation project using weighted grey target model.Choose the best project by the result.Finally, this paper taking X power supply company's three projects as an example,approved that the evaluation index system and model of evaluation had better practicability and feasibility.The system has some reference value to the right technology innovation project decision by power grid company.

\section{References}

[01] Yongxiu He, Comprehensive evaluation method and application of electric power ,M. China electric power press.2011.

[02] Guibin Zhang, The reliability of the power grid operation research ,J. Science and technology wizard.36( 2011)238-253.

[03] McAfee A, Brynjolfsson E.Big data:The management revolution ,J. Boston:Harvar Business Review.10(2012)3-9.

[04] Mingwei Sun, Information policy based on the theory of the weighted grey target decision scheme selection, J. The intelligence theory and practice,.7(2012) 101-103. 
[05] Jie Song, Plus or minus the bull 's-eye grey target decision model,J. Systems Engineering-Theory \& Practice.36(2010) 445-447.

[06] Jingmin Wang, The multi-target grey target model based on interval Numbers in the evaluation of the smart grid applications ,J. East China Electric Power.10(2011) 126-129. 